\title{
An Empirical Examination of Cumulus Entrainment ${ }^{1}$
}

\author{
Peter W. Sloss \\ Universily of Chicago, Ill. \\ (Manuscript received 1 May 1967, in revised form 13 June 1967)
}

\begin{abstract}
Most analytic theories and laboratory models of cumulus entrainment predict that the rate of influx of ambient fluid into a convective element depends inversely on the diameter of the updraft zone. A study of 15 continental cumulus congestus clouds containing apparent bubble-like rising elements failed to demonstrate the predicted radius dependence. Application of a standard one-dimensional entrainment computation to the measured cloud and environment conditions revealed no significant correlation between cloud dimensions and entrainment.
\end{abstract}

\section{Entrainment model}

In its simplest form the dynamics of cumulus convection reduces to a height-dependent mass and energy balance. To a first approximation we may regard the history of a rising parcel of air as a sequence of quasistatic processes, each of which goes to completion so that the resultant system proceeds as a whole. Any one of these steps is as follows:

1) Lift a parcel of cloud over some height interval, retaining all condensate.

2) Mix the parcel with some amount of ambient air and equilibrate temperature without allowing condensation or evaporation.

3) Equilibrate excess liquid water and vapor to bring the total mixture to its wet-bulb point. ${ }^{2}$

With various embellishments these steps form the basis of several models of convective mixing (Stommel, 1947; Austin, 1951; Turner, 1962; Squires and Turner, 1962; Simpson et al., 1965). A common feature of many of these discussions of entrainment is the invocation of an inverse diameter dependence based on the surface to volume relation of a cylindrical element of unit thickness. Is this relation borne out in real clouds?

To define a system undergoing the process described above it is necessary to account for all of the mass of both air and water and the total energy, both sensible and latent heat. To do this ideally one would like to have complete soundings of temperature and humidity throughout the cloud and its environment plus the distribution of condensed water in the cloud. A lack of the hardware necessary for such a rigorous definition of the system leads to some perhaps unfortunate but apparently unavoidable one-dimensional approximations.

\footnotetext{
1 Research supported by the National Science Foundation under Grants GP 3779 and GP 3881

This computation when done on a Stave diagram actually gives the pseudo wet-bulb potential temperature but the difference is negligible [see Rao (1960)].
}

\section{The measurements}

The data for this discussion were collected during four research flights during July and August, 1965, over the vicinity of Bemidji, Minn. Parameters pertinent to this study are dry-bulb temperature (sampled by a platinum-resistance bridge in a reverse-flow housing), liquid water content (sampled by a JohnsonWilliams hot-wire instrument), airspeed and altitude (measured by strain-gage transducers fed from standard pitot-static tubes). All quantities were recorded on a Honeywell 1108 Visicorder on board the airplane. Various other timing and identifying traces were also recorded. A sample of a cloud penetration record is reproduced in Fig. 1. In-cloud data were computed for the warmest and wettest part of the cloud. Although this is a deviation from the "top-hat" assumption used in most of the literature, it is obvious that taking the warmest in-cloud point as characteristic leads to a minimum value of the proportion of entrained air and that the error in this assumption should be of the same order for a sample of similar clouds such as is being examined here. Fig. 2 shows some examples of the type of cloud chosen for this study. The crosses indicate the approximate entry point of the aircraft as determined from the geometry of the photographs from which the figures were traced and the known heading and altitude of the aircraft. It is greatly to the credit of our chief pilot, Mr. James Farrell, that the penetration points were so consistently near the center of the active portion of each cloud. This sometimes resulted in a hairraising ride that was proof positive that the core of the cloud had been found! Note the bubble-like shape of cloud $665-\mathrm{D}$, from which the temperature and liquid water data in Fig. 1 were taken.

In some cases the flight path dimension chosen as $D$ was not the entire diameter of the visual cloud, but rather the distinctly warmer and wetter part of the pass having a form similar to Fig. 1. For example, cloud 


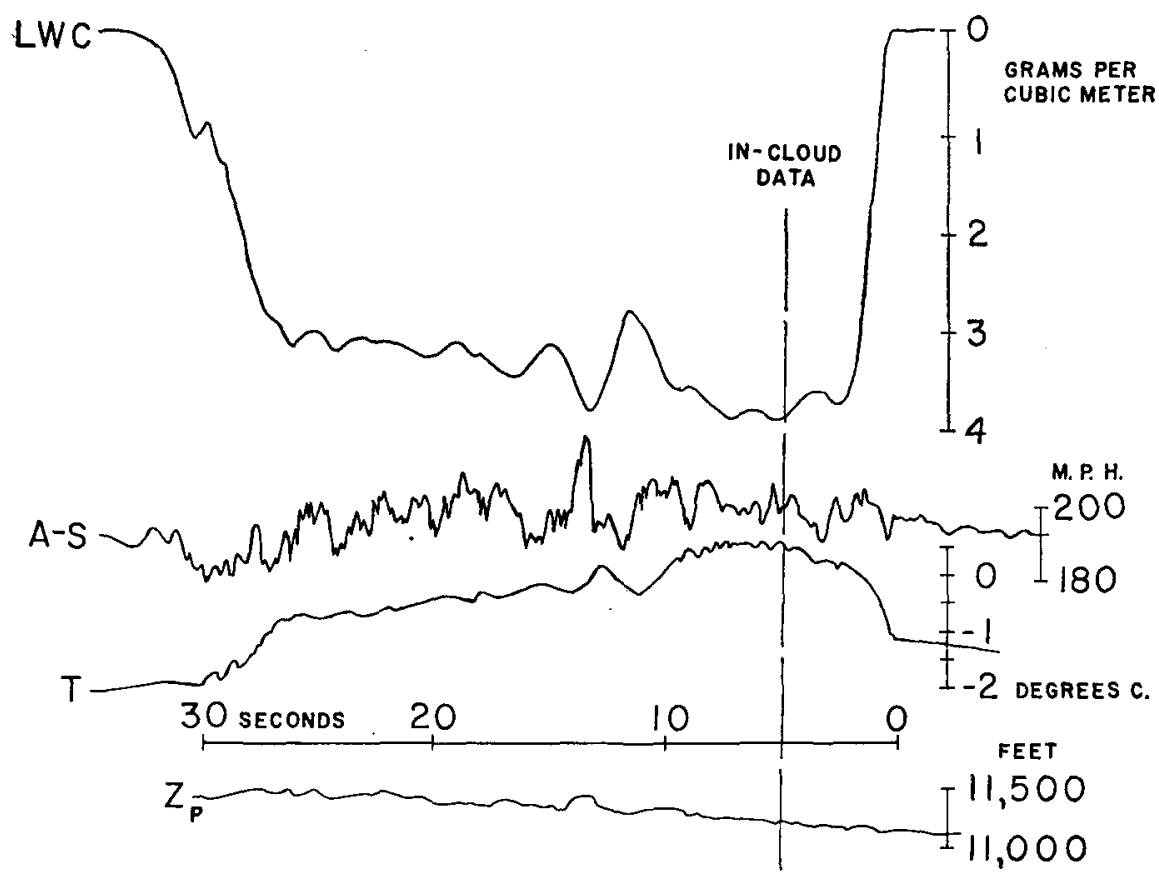

Fig. 1. Sample record of parameters taken in transit of a cloud (data from 3 August 1965 , cloud D).

665-A-2 shown in Fig. 2 is larger than the dimension $D$ quoted in Table 1, but a large portion of the total traverse appeared to be "junk" and only a fresh, sharply-defined bubble at the entry point on the upwind side was measured. The back of the cloud appeared to have conditions similar to the ambient field and the shorter path length through the bubble was chosen. In clouds 665-B and 669-A, two separate bubbles were measured but it was impossible to keep track of their identities. Dimensions are given for each bubble as a separate pass.

It should be noted that there is some difficulty in determining the proper dimension $D$. Geometric determination of $D$ from photographs taken by a $16-\mathrm{mm}$ timelapse camera pointed out the front of the aircraft gives dimensions ranging from about two-thirds to one and one-half times the length measured through the cloud. While the point of entry into the cloud may be located to a good degree of certainty by examining the relative displacement of identifiable features of the cloud on successive movie frames, measurement of the size of the cloud remains only approximate.

Temperatures characteristic of the clear air surrounding each cloud were determined from a sounding made by the aircraft as it climbed to working altitude and taken for consistency checks just upwind of clouds about to be entered. Malfunctions in the airborne wet-bulb thermometer and dew-point hygrometer necessitated the use of humidity data from the nearest possible radiosonde stations which were Bismarck, N. D., and
International Falls, Minn. These data are certainly not perfectly descriptive of the moisture conditions in the research area, but are the best available.

Table 1 lists research days, flight code numbers, cloud identification numbers and measured in-cloud temperature $T_{m}$, ambient temperature $T_{a}$, height above cloud base $\Delta Z$, cloud dimension along flight path $D$, and per cent mass entrained $E$ in $1 \mathrm{~km}$.

\section{Entrainment rates and cloud diameters}

Entrainment rates were calculated using a single interval from cloud base to measurement level, mixing in-cloud, and clear-air temperatures and mixing ratios at the upper level. Calculations using mixing at intermediate levels were tried but several test cases showed differences in results that were inside the order of accuracy of the measurements themselves. This may be a consequence of the linearity of the lapse rates on the days tested, but the single-step assumption seems valid for this purpose.

Values of entrainment $E$ were determined by the best match of temperature calculated from the mixing model and temperature measured in the actual cloud. Note that the result is not necessarily constant for successive passes on the same cloud.

Almost all cloud sizes may be represented on a given day, yet no single day's clouds nor the aggregate of all days' clouds demonstrate an inverse size dependence of entrainment. A comparison of entrainment rate and cloud diameter is presented in Fig. 3. 

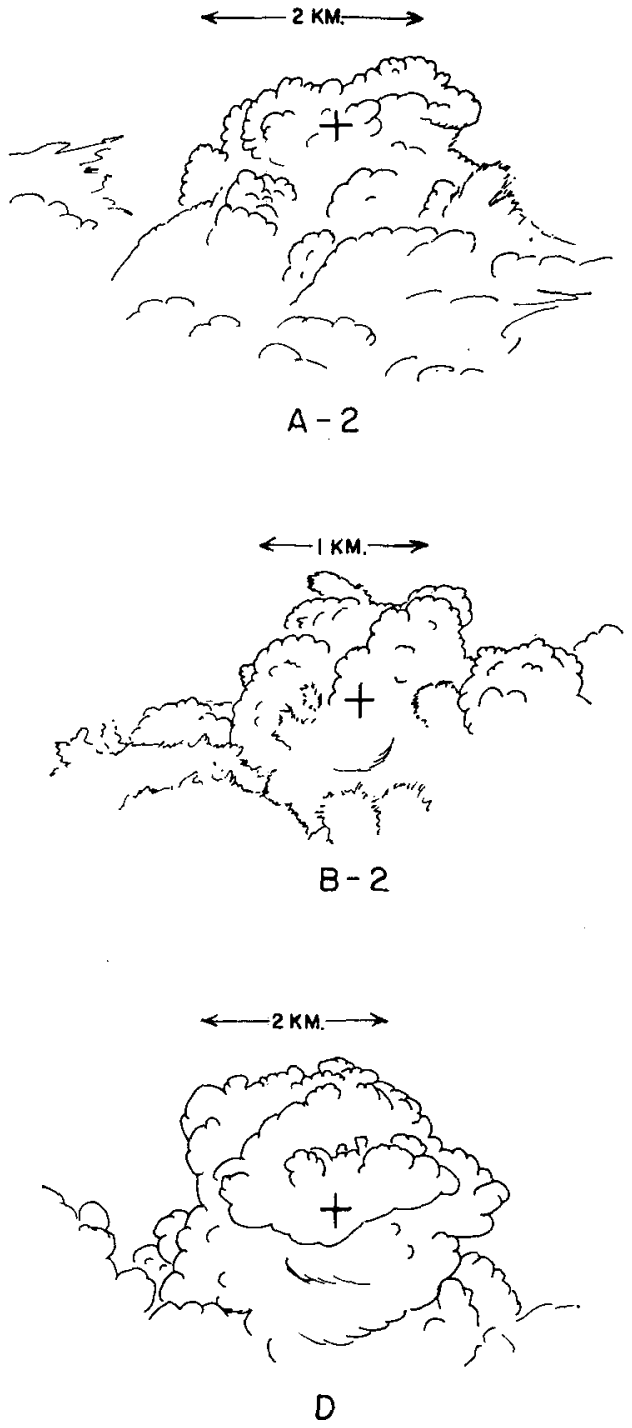

FLIGHT 665

3 AUG 65

FIG. 2. A representative sample of cloud shapes examined in this study. Crosses indicate approximate aircraft pointof-entry.

\section{Conclusions}

It appears inescapable that there exists an incompatability between the one-dimensional mixing models and the clouds investigated here. It has been found in other investigations (Simpson et al., 1965) that some tropical cumuli appear to exhibit the "expected" inverse-diameter dependence and it appears from these studies that even the full parcel-ascent model might hold for the larger clouds. The clouds studied in Minnesota differed from tropical clouds both in environment and microstructure, and they might well be expected to differ on their response to convective mixing.

The choice of clouds for this study was based on the closest possible visual resemblance of the clouds to convective bubbles. Clouds that appeared to be decaying and disorganized were deleted from the sample. Since the purpose of this investigation was to examine the applicability of the commonly used one-dimensional entrainment computation, every attempt was made to pick appropriate clouds. That such clouds were scarce indicates the infrequency of "model-fitting" conditions.

The presence of nearby clouds and the general wind

TABLE 1. Measured cloud parameters and calculated ent rainment rates.

\begin{tabular}{|c|c|c|c|c|c|}
\hline $\begin{array}{l}\text { Cloud } \\
\text { identifi- } \\
\text { cation }\end{array}$ & $\underset{\left({ }^{\circ} \mathrm{C}\right)}{T_{m}}$ & $\underset{\left({ }^{\circ} \mathrm{C}\right)}{T_{a}}$ & $\underset{(\mathrm{km})}{\Delta Z}$ & $\underset{(\mathrm{km})}{D}$ & $\begin{array}{c}E \\
\left(\% \mathrm{~km}^{-1}\right)\end{array}$ \\
\hline \multicolumn{6}{|c|}{$\begin{array}{l}\text { Flight } 662 \\
30 \text { July } 1965 \text { (Cloud bases at } 922 \mathrm{mb}, 17.1 \mathrm{C} \text { ) }\end{array}$} \\
\hline $\begin{array}{l}\text { A-1 } \\
\text { B-3 } \\
\text { C-1 } \\
\text { C-2 }\end{array}$ & $\begin{array}{r}-0.7 \\
-3.1 \\
0.2 \\
2.1\end{array}$ & $\begin{array}{l}-1.3 \\
-1.3 \\
-0.8 \\
-0.8\end{array}$ & $\begin{array}{l}3.2 \\
3.2 \\
2.8 \\
2.8\end{array}$ & $\begin{array}{l}1.3 \\
0.3 \\
0.2 \\
3.1\end{array}$ & $\begin{array}{r}6 \\
19 \\
9 \\
8\end{array}$ \\
\hline
\end{tabular}

Flight 664

2 August 1965 (Cloud bases at $824 \mathrm{mb}, 10.6 \mathrm{C}$ )

$\begin{array}{lrrrrr}\text { A-1 } & -0.7 & -3.2 & 1.7 & 1.3 & 19 \\ \text { B-1 } & -0.9 & -2.3 & 1.7 & 0.7 & 19 \\ \text { B-5 } & -1.4 & -2.2 & 1.7 & 1.6 & 23 \\ \text { C-1 } & 0.2 & -3.2 & 1.8 & 3.0 & 6 \\ \text { C-2 } & -1.4 & -3.5 & 1.8 & 1.7 & 16 \\ \text { C-4 } & -1.0 & -2.2 & 1.8 & 4.1 & 16 \\ \text { C-6 } & 0.5 & -2.1 & 1.7 & 2.9 & 7 \\ \text { D-1 } & -5.7 & -5.7 & 2.4 & 2.9 & 25 \\ \text { D-3 } & -4.7 & -5.7 & 2.4 & 0.5 & 19\end{array}$

Flight 665

3 August 1965 (Cloud bases at $818 \mathrm{mb}, 10.2 \mathrm{C}$ )

$\begin{array}{lrrrrr}\text { A-1 } & -2.7 & -3.3 & 1.8 & 1.3 & 14 \\ \text { A-2 } & -2.3 & -2.4 & 1.7 & 0.8 & 37 \\ \text { A-3 } & -1.4 & -1.3 & 1.7 & 2.5 & 34 \\ \text { B-1a } & -1.3 & -2.1 & 1.7 & 0.2 & 30 \\ \text { B-1c } & -0.5 & -2.4 & 1.7 & 1.2 & 16 \\ \text { B-2 } & -0.2 & -1.5 & 1.6 & 1.9 & 25 \\ \text { B-3 } & -0.2 & -2.3 & 1.7 & 1.5 & 20 \\ \text { B-4 } & -1.1 & -1.2 & 1.6 & 2.4 & 34 \\ \text { C-1 } & -0.2 & -1.2 & 1.7 & 2.6 & 20 \\ \text { C-2 } & -0.6 & -1.1 & 1.7 & 0.3 & 23 \\ \text { C-3 } & -0.6 & -1.2 & 1.6 & 0.6 & 23 \\ \text { C-4 } & -0.7 & -1.2 & 1.7 & 1.2 & 23 \\ \text { C-5 } & -0.6 & -1.2 & 1.6 & 2.2 & 23 \\ \text { D-1 } & 0.6 & -1.4 & 1.6 & 2.7 & 17 \\ \text { E-1 } & 9.3 & -0.4 & 1.6 & 2.0 & 14 \\ \text { F-1 } & 0.0 & -0.1 & 1.7 & 2.1 & 24 \\ \text { F-2 } & 0.6 & -0.9 & 1.6 & 2.3 & 15 \\ \text { I.-3 } & -0.5 & -0.9 & 1.6 & 2.8 & 34\end{array}$

Flight 669

16 August 1965 (Cloud bases at $849 \mathrm{mb}, 14.5 \mathrm{C}$ )

$\begin{array}{llllll}\text { A.1 } & -1.2 & -2.8 & 2.4 & 1.6 & 15 \\ \text { A-2 } & -0.5 & -3.6 & 2.4 & 2.5 & 12 \\ \text { A.3a } & -1.0 & -2.8 & 2.4 & 0.6 & 15 \\ \text { A.3b } & -1.4 & -2.8 & 2.4 & 1.5 & 16 \\ \text { A } 4 & -1.2 & -3.4 & 2.5 & 0.9 & 13 \\ \text { A.5 } & -1.8 & -2.1 & 2.4 & 1.1 & 19 \\ \text { A.6 } & -1.6 & -2.1 & 2.4 & 1.8 & 18 \\ \text { A.7 } & -0.5 & -2.1 & 2.4 & 2.9 & 13 \\ \text { B.1 } & -0.7 & -2.1 & 2.4 & 0.8 & 14\end{array}$




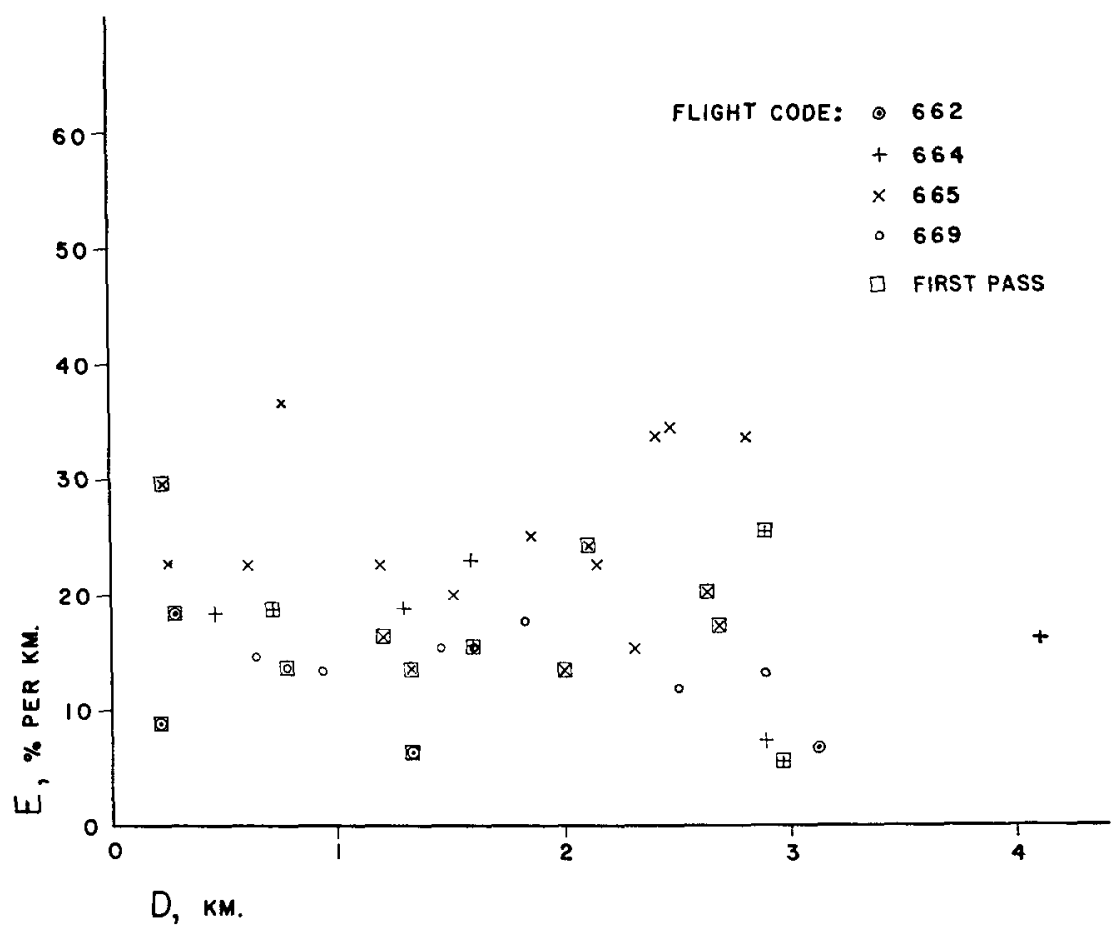

FIg. 3. Comparison of Pentrainment rate $E$ expressed as per cent mass gained in 1 $\mathrm{km}$ of ascent vs. cloud diameter along flight path $D$. The first pass through a new cloud is identified by a square.

field perturb the horizontal homogeneity inherent in a one-dimensional model. As Lilly (1962) pointed out, although it would be best to use complete boundary conditions in three dimensions, the computations of the total mixing process and cloud dynamics become intractable. Also, complete boundary data could not be collected. As Table 1 indicates, there was good consistency in ambient temperature for passes at the same level, even for different clouds in different places at different times. This serves to support an assumption of horizontal homogeneity, but the one-dimensional entrainment calculations show no inverse-diameter dependence. Since the clouds were picked as the best available to fit to the one-dimensional model, it is tempting to say that the model is not applicable to the degree of generality that is commonly assumed.

Acknowledgments. The author wishes to thank Prof.
Roscoe R. Braham, Jr., and the University of Chicago Cloud Physics Project for their aid and patience.

\section{REFERENCES}

Austin, J. M., 1951 : Cumulus convection and entrainment. Compendium of Meleorology, Boston, Amer. Meleor. Soc., p. 694.

Lilly, D. K., 1962: On the numerical simulation of buoyant convection. Tellus, 14, 148-172.

Rao, K. N., 1960 : Difference between wet-bulb temperature $\left(T_{w}\right)$ and pseudo-wet-bulb temperature $\left(T_{s w}\right)$. Beitr. Phys. Atmos., $32,202$.

Simpson, J., R. H. Simpson, D. A. Andrews and M. A. Eaton, 1965: Experimental cumulus dynamics. Reviews of Geophysics, 3, 387-431.

Squires, P., and J. S. Turner, 1962: An entraining jet model for cumulonimbus updraughts. Tellus, 14, 422-434.

Stommel, H., 1947: Entrainment of air into a cumulus cloud. J. Meteor., 4, 91-94.

Turner, J. S., 1962: The "starting plume" in neutral surroundings. J. Fluid Mech., 13, 356-368. 